\title{
ANÁLISE DA INCLUSÃO SOCIAL DOS IDOSOS NOS PARQUE URBANOS A importância da academia ao ar livre para os idosos frequentadores dos parques
}

\section{ANAL YSIS OF ELDERLY SOCIAL INCLUSION IN URBAN PARKS The importance of the outdoor gym for the elderly}

\author{
A. Thaís Corrêa Cabral \\ PPG FAU, Programa de Pesquisa e Pós-Graduação Faculdade de Arquitetura e Urbanismo; \\ Universidade de Brasília, Brasil \\ arqthaiscabral@gmail.com
}

\begin{abstract}
RESUMO
Os espaços públicos das cidades são, muitas vezes, hostis à presença daqueles que não têm completo domínio de suas funções. É comum encontramos idosos que preferem não sair de casa por conta das dificuldades que encontram em se locomover pela cidade. No entanto, o convívio e a possibilidade de interagir com o espaço que os rodeia é requisito fundamental para o envelhecimento saudável. Pensando nisso, fez-se essa pesquisa voltada à análise de como tornar os parques públicos espaços inclusivos para os idosos. Por meio do instrumento SOPARC, que se baseia na observação sistemática de pessoas, concluiuse que a presença de Academias ao Ar Livre nos parques urbanos tem grande efeito positivo na qualidade $e$ quantidade de atividades físicas e interação dos idosos nesses espaços. Além disso, podem-se observar várias melhorias que a presença destes equipamentos traz às pessoas de terceira idade, favorecendo sua interação com todas as outras faixas etárias.
\end{abstract}

Palavras-chave: parques urbanos, idosos, academia ao ar livre, espaços públicos.

Linha de Investigação: 1. Cidade e projeto. Tópico: Projeto urbano e espaço público.

\begin{abstract}
Public spaces in cities are often hostile to those who do not have complete mastery of their functions. It is common to find elderly people who prefer not to leave their home because of the difficulties they find in getting around the city. However, conviviality and the possibility to interact with the space that surrounds them is a fundamental requirement for healthy aging. With this in mind, this research aimed at analyzing how to make public parks inclusive spaces for the elderly. Through the SOPARC methodology, which is based on the systematic observation of people, it was concluded that the presence of Outdoor Academies in urban parks has a great positive effect on the quality and quantity of physical activities and interaction of the elderly in these spaces. In addition, it was possible to observe several improvements that the presence of this equipment brings to the elderly, favoring their interaction with all other age groups.
\end{abstract}




\section{SÃO PAULO15 17 LISBOA $25 \sim 26$ JUN 2020

\section{Introdução}

O significativo aumento populacional brasileiro e o crescimento contínuo do contingente de pessoas com 60 anos, ou mais, fizeram com que houvesse uma maior procura por pesquisas e debates nessa área, o que ajuda os idosos a terem uma vida com mais qualidade e autonomia. Diante dessa realidade, as cidades e seus espaços públicos precisam estar mais bem preparados e adaptados para apoiarem o desejável envelhecimento ativo das pessoas mais velhas. Os parques, praças, ruas e outros locais abertos, presentes nas imediações das residências, são os espaços urbanos públicos de livre acesso que promovem encontros sociais e permitem a realização de atividades físicas, recreativas, culturais e de lazer.

A Organização Mundial da Saúde (OMS) considera o envelhecimento ativo (World Health Organization, 2005) um processo contínuo, determinado por vários fatores que, isolados ou em conjunto, contribuem para a saúde, a participação e a segurança, com o objetivo de melhorar a qualidade de vida à medida que as pessoas ficam mais velhas. Uma vida ativa melhora a saúde mental e, frequentemente, promove contatos sociais.

No paradigma atual, o idoso é um ser ativo que se realiza no exercício de suas habilidades mentais, afetivas, físicas e sociais, resultando em uma condição de extensão de suas capacidades (Silva e Elali, 2015). Silva \& Elali apontam que as praças são locais propícios para que os idosos possam usufruir do lazer ativo e passivo. A meu ver, essa observação também pode ser estendida para os parques. Parques são meios importantes na promoção da vida ativa e da saúde geral em amplos segmentos da população, mas a capacidade deles de aumentar os níveis de atividade física não é totalmente realizada.

Independente das razões que levam as pessoas a estarem no espaço público (necessidade ou vontade), há atividades que decorrem da copresença: as vinculadas à interação entre as pessoas: as chamadas atividades sociais, ou resultantes (Tenorio, 2012). Gehl esclarece que um espaço público de boa qualidade é aquele que favorece as três atividades: necessárias, opcionais e sociais (Gehl, 2011).

Os idosos frequentam os parques por disponibilizarem equipamentos esportivos e proporcionarem segurança, acessibilidade, integração social e momentos de contemplação. Dentre os equipamentos que os parques oferecem, existe a Academia ao Ar Livre (AAL), conhecida no Distrito Federal (DF) como Ponto de Encontro Comunitário (PEC) ou, ainda, como Academia da Terceira Idade (ATI). São espaços não cobertos compostos por um conjunto de aparelhos de musculação, com informações sobre os dispositivos, destinados à população de forma gratuita para que se possa realizar exercícios físicos, socializar e melhorar a qualidade de vida.

No Brasil, as AALs começaram a ser instaladas em 2005 a partir do Programa Brasil Saudável, lançado pelo Ministério da Saúde para o cumprimento das diretrizes e ações previstas na Estratégia Global de Alimentação e Atividade Física- 2004, proposta pela OMS (Pieri, 2015). As academias são compostas por 10 equipamentos multifuncionais de ginástica, com cores vibrantes, feitos para cumprir funções de alongar, fortalecer e desenvolver a musculatura, trabalhar a capacidade aeróbica e coordenação motora (Secretaria de Educação Governo do Estado do Paraná, 2014).

Os aparelhos comumente instalados são: esqui, rotação dupla diagonal, surf, simulador de caminhada, pressão das pernas, alongador, simulador de cavalgada, multi-exercitador, rotação vertical, remada sentada. No total, cerca de 28 pessoas podem fazer exercícios ao mesmo tempo, uma vez que alguns dos equipamentos permitem a utilização de duas a quatro pessoas a um só tempo. Os aparelhos são instalados em cima de uma base em concreto estrutural usinado. Os equipamentos de musculação utilizam do peso do 


\section{SÃO PAULO15 $\sim 17 \cdot$ LISBOA $25 \sim 26$ JUN 2020 \\ Seminário Internacional de \\ Seminario Internacional de Investigação em Urbanismo Investigación en Urbanismo}

corpo do próprio indivíduo para desenvolver os exercícios. As academias foram previstas para o público a partir dos 12 anos, mas são, normalmente, utilizadas por pessoas acima dos 60 anos

O Instituto do Meio Ambiente e dos Recursos Hídricos (IBRAM) administra, hoje, no Distrito Federal, 51 parques ecológicos e parques urbanos e conta com outras 33 Unidades de Conservação de proteção integral ou de uso sustentável. De acordo com o último Guia de Parques do Distrito Federal (Instituto de Meio Ambiente e dos Recurso Hídricos, 2013), apenas 33 parques são considerados em condições de receber visitantes para a realização de atividades físicas, de lazer ou contemplação. Existem ainda, em Brasília, outros 15 parques urbanos cuja gestão é realizada pela sua respectiva Região Administrativa e pela Secretaria de Esportes, e alguns outros que se encontram em processo de transferência (Ibram, 2020). O Parque Nacional de Brasília está sob gestão do Instituto Chico Mendes de Conservação da Biodiversidade (ICMBio, 2020).

O Parque Ecológico dos Jequitibás, objeto de estudo desta pesquisa (Fig. 01), enquadra-se na categoria de unidade de conservação como Parque Ecológico conforme Lei Complementar n827, de 2010, que institui o Sistema Distrital de Unidades de Conservação da Natureza (SDUC), e é gerido pelo IBRAM.

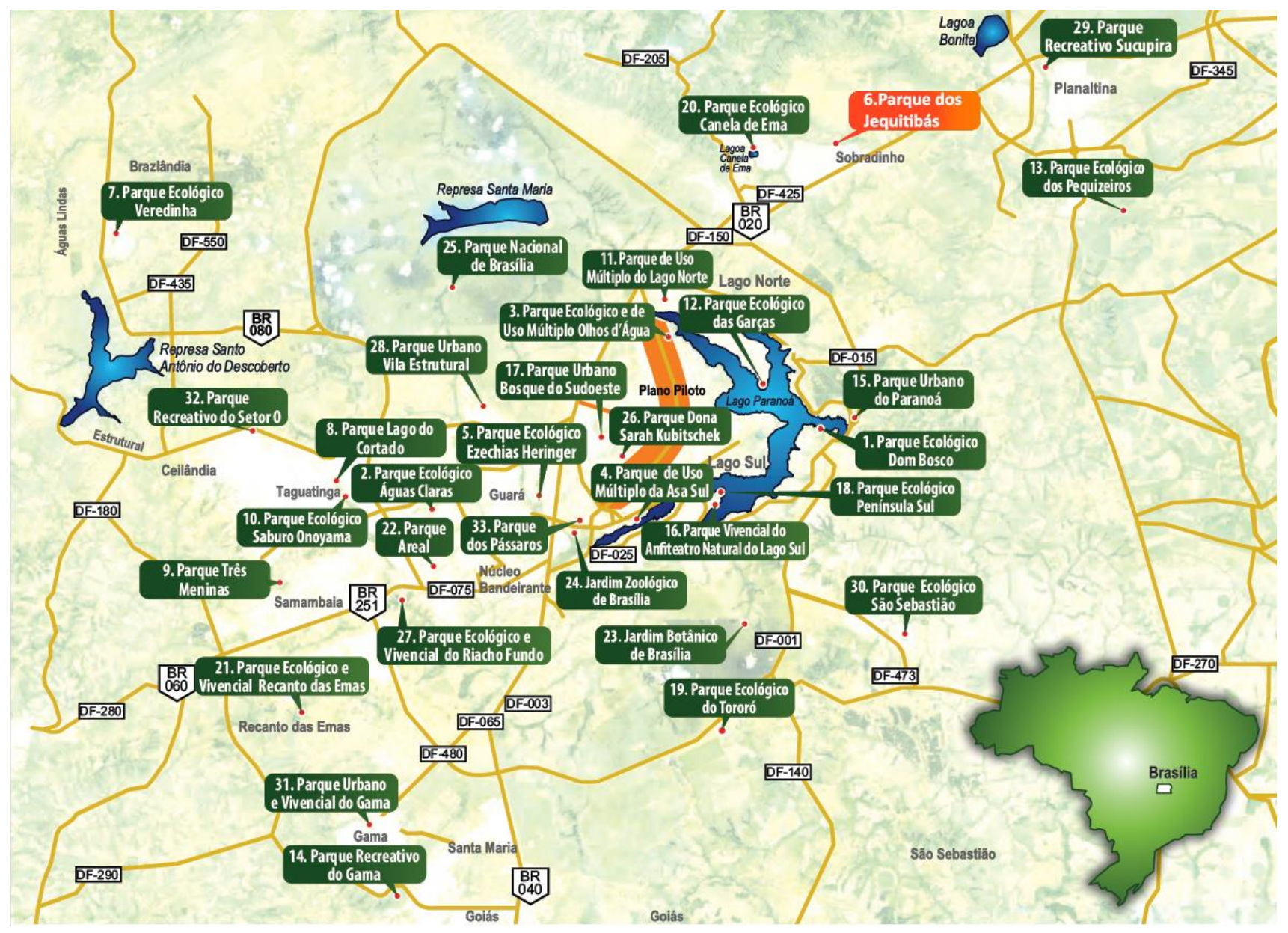

Fig. 01 Parques do DF. Fonte: Adaptado de Instituto de Meio Ambiente e dos Recurso Hídricos, 2013. 


\section{SÃO PAULO15 17 LISBOA $25 \sim 26$ JUN 2020}

O objetivo do parque ecológico é:

conservar amostras dos ecossistemas naturais, da vegetação exótica e paisagens de grande beleza cênica; propiciar a recuperação dos recursos hídricos, edáficos e genéticos; recuperar áreas degradadas, promovendo sua revegetação com espécies nativas; incentivar atividades de pesquisa e monitoramento ambiental e estimular a educação ambiental e as atividades de lazer e recreação em contato harmônico com a natureza (Brasil, 2010: 4).

Este estudo tem como objetivo investigar a importância do PEC para a população idosa frequentadora do Parque Ecológico dos Jequitibás quanto à inclusão social entre os idosos e, também, com outras gerações, além do seu papel na promoção do envelhecimento ativo. O parque estudado está inserido na malha urbana da Região Administrativa de Sobradinho- RA V, no Distrito Federal, Brasil. Fez-se um comparativo com e sem a presença dos aparelhos de ginástica, uma vez que o parque ficou o período de duas semanas sem o PEC, pois haviam sido enviados para manutenção e retornaram devido à ação da comunidade local.

A hipótese é de que, sem a presença dos equipamentos esportivos no parque, o número de frequentadores idosos cairia e as demais infraestruturas oferecidas não seriam suficientemente atrativas para que essa parcela da população continuasse frequentando o espaço. Acredita-se que, com a presença do PEC, é possível promover convívio social tanto entre os idosos quanto entre outras gerações.

Com essa hipótese em vista, realizou-se o estudo no Parque Ecológico dos Jequitibás. Foram feitas as seguintes perguntas:

- O público idoso é a parcela da população que mais utiliza os aparelhos?

- O parque continuou servindo ao seu propósito de atividades esportivas e de lazer para os idosos, sem a presença do PEC?

- O número de frequentadores idosos diminuiu, ou permaneceu o mesmo?

- Surgiram novas práticas?

- O PEC é um ponto promotor de inclusão social?

Para a obtenção das respostas, realizou-se o estudo de caso em um dia de semana típico e em dia de final de semana, com e sem a presença da AAL, nos seguintes períodos: manhã, almoço, tarde, e horário de fechamento do parque.

\section{Objeto de Estudo}

O Parque Ecológico dos Jequitibás pertence à RA Sobradinho (Fig. 02), que foi fundada em 13 de maio de 1960, e foi oficializada pelo Decreto no 571, de 1967 (GDF, 2019). Hoje, é reconhecida como sendo a RA V e está inserida na Unidade de Planejamento Territorial (UTP) Norte. Seu objetivo era o de abrigar a população que participava da construção de Brasília e de ampliar a produção agrícola do DF. 


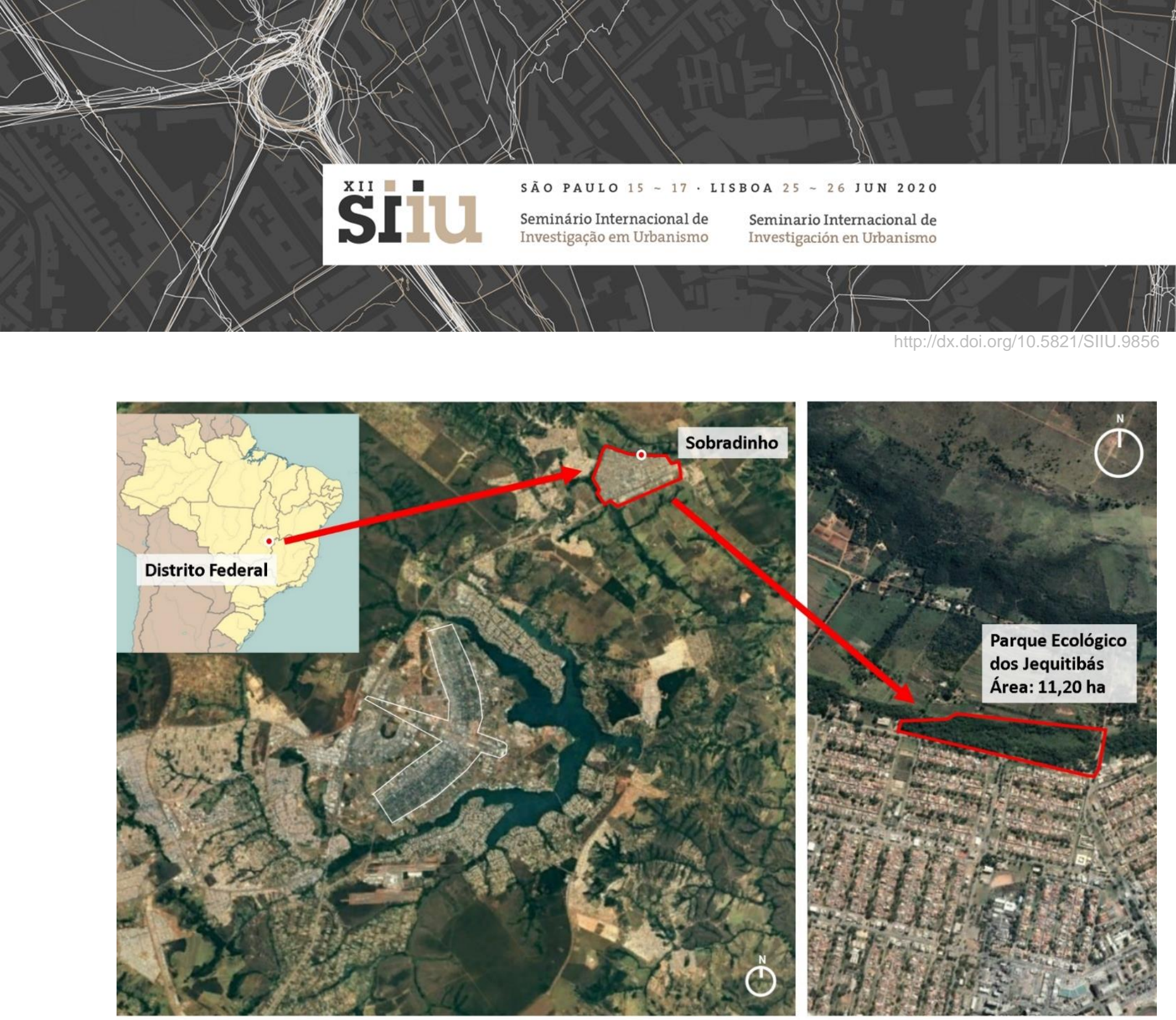

Fig. 02 Localização do Parque Ecológico dos Jequitibás. Fonte: Adaptado de Google Earth Pro, 2018.

A Pesquisa Distrital por Amostra de Domicílios (PDAD) 2018: Sobradinho (Codeplan, Sefp e Gdf, 2018) aponta que a população é de 60.077 pessoas; desse total, 8.305 são idosos, correspondendo a $13,8 \%$. A faixa etária de 60 a 64 anos é a que possui mais idosos, com 2.554, cerca de 30,8\%.

Na RA Sobradinho, o valor da renda domiciliar estimada é de $R \$ 5.889,90$, que resulta em um valor médio por pessoa de $\mathrm{R} \$ 2.127,10$. No que tange à desigualdade, o índice de Gini da renda domiciliar foi de 0,49; enquanto para a renda por pessoa foi de 0,51 . O valor do salário mínimo de 2018 considerado é de $R \$$ 954,00 . Sobre a distribuição do rendimento domiciliar por faixas de salário mínimo 35,8\% responderam ter mais de 2 a 5 salários mínimos.

No quesito infraestrutura urbana nas proximidades dos domicílios, $62,6 \%$ dos respondentes confirmaram a existência de quadras esportivas, para $60,2 \%$ existe PEC, para $57,5 \%$ há parques e jardins nas proximidades e para $32 \%$ existem ciclovias ou ciclo faixas nas proximidades. Sobre a questão de segurança $52,2 \%$ respondentes confirmaram a existência de policiamento regular.

O parque está localizado entre a margem esquerda do ribeirão Sobradinho e à direita da Avenida Contorno. Foi criado pelo Decreto no 16.239 (Instituto Socioambiental, 2013-2016), de 28 de dezembro de 1994, e possui 11,20 hectares de área. A partir do decreto no 38.368, de 26 de julho de 2017, o parque passou a ser denominado como Parque Ecológico dos Jequitibás e é administrado pelo IBRAM.

O extenso espaço gramado que antecede a mata, com árvores de grande porte como os Jequitibás, é o local onde foram implantadas as estruturas de atendimento ao público. Abriga área de mata ripária parcialmente 


\section{SÃO PAULO15 $\sim 17 \cdot$ LISBOA $25 \sim 26$ JUN 2020

preservada, por onde flui o Ribeirão Sobradinho. O parque possui área destinada ao lazer e desporto da comunidade, como a Academia ao Ar Livre, circuito inteligente de ginástica, quiosque de madeira, sede administrativa, banheiros públicos, bebedouro, pergolado, parque infantil, quadra poliesportiva, anfiteatro, pista de skate, ducha, pista de caminhada com piso intertravado que interliga os espaços e trilhas de terra que adentram a mata. Na área externa, há uma pista de caminhada e ciclofaixa, paralelas à Av. Contorno. $\mathrm{O}$ perímetro do parque é cercado parcialmente por alambrado, porém, no lado Norte, vizinho às chácaras, é quase inexistente a cerca de arame. Possui uma entrada principal para pedestres e uma entrada lateral para carros, que dá acesso ao estacionamento interno. Seu horário de funcionamento é das $6 \mathrm{~h}$ até às $18 \mathrm{~h}$, com vigilância ostensiva.

\section{Metodologia}

A pesquisa de campo utilizou-se de uma abordagem multimetodológica que incluiu a adaptação do Sistema de Observação de Atividades Físicas e Recreativas na Comunidade, conhecido pela sigla em inglês SOPARC (Mckenzie e Cohen, 2006), desenvolvida por Thomas L. McKenzie e Deborah A. Cohen, em congruência com mapas comportamentais das áreas previamente selecionadas, de acordo com os parâmetros difundidos por Jan Gehl e sua equipe (Gehl e Svarre, 2018), além de entrevistas semiestruturadas e registros fotográficos. A metodologia empregada permitiu a obtenção dos dados quantitativos e qualitativos, de forma a focalizar no que era essencial e preciso.

Os resultados obtidos por meio da ferramenta de contagem nos permitem identificar a vida pública em uma cidade. A contagem fornece dados quantitativos que podem ser utilizados para se comparar 0 antes e o depois de um determinado local e ao longo de um período. Foi para essa função que se utilizou a ferramenta SOPARC, empregada em parques para a obtenção de informações diretas sobre o uso do parque, suas características e de seus usuários. O sistema fornece uma avaliação dos níveis de atividades física desenvolvidos pelos usuários, quantitativo de pessoas, gênero, tipos de atividade físicas e a faixa etária estimada.

O método consiste na divisão espacial do parque por setores previamente identificados e mapeados, no qual, em cada área-alvo, haverá um ponto fixo e estratégico que permitirá a realização da varredura visual e uma avaliação momentânea do tempo, pelo pesquisador, para o registro dos usuários e suas atividades. São realizadas duas varreduras em um mesmo período, a segunda rodada inicia-se meia hora depois do início da primeira, para que, no final, sejam somados o quantitativo de pessoas e obtenha-se a estimativa daquele período.

Adaptando-se para essa pesquisa o instrumento SOPARC, que cataloga em fichas as informações referentes aos usuários e parque, a coleta das informações específicas foi registrada diretamente em mapas comportamentais das áreas previamente selecionadas, cópias das quantas sejam as horas de contagem. Para facilitar a contagem, foram escolhidos símbolos geométricos que representassem: crianças (até 12 anos), adolescentes (de 13 a 20 anos), mulheres e homens (de 21 a 59 anos) e idosas e idosos (com 60 anos ou mais), e a posição em que se encontravam: em pé, sentado, deitado e agachado.

No mapa, tomou-se nota, também, das atividades que estavam sendo realizadas e se as pessoas estavam interagindo entre si, representadas ao circunscrever os elementos. As atividades foram classificadas em três níveis: atividade sedentária (indivíduo deitado, sentado ou parado em pé, com frequência cardíaca baixa), 


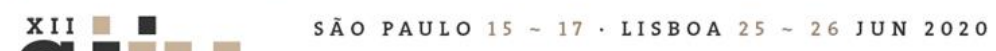

Seminário Internacional de Investigação em Urbanismo

atividade moderada (indivíduo caminhando em ritmo tranquilo) e atividade vigorosa (indivíduo muito ativo, com frequência cardíaca aumentada).

O parque Jequitibás foi dividido em dez áreas-alvos (Fig. 03). As áreas foram observadas na mesma ordem rotacional, da esquerda para a direita, de maneira padrão para todos os dias em que foram realizadas a contagem. As observações foram realizadas para a obtenção da estimativa do fluxo padrão do parque, realizadas em dias sem chuva e em dias com e sem a presença da AAL. A pesquisa ocorreu em dias típicos de semana e final de semana (Tenorio, 2012). Foram escolhidas, para representar os dias de semana típico, as terças-feiras dos dias 12.11.2019 (sem AAL) e 26.11.2019 (com AAL). Já os sábados, 09.11.2019 (sem AAL) e 14.12.2019 (com AAL) representaram os dias típicos de final de semana.

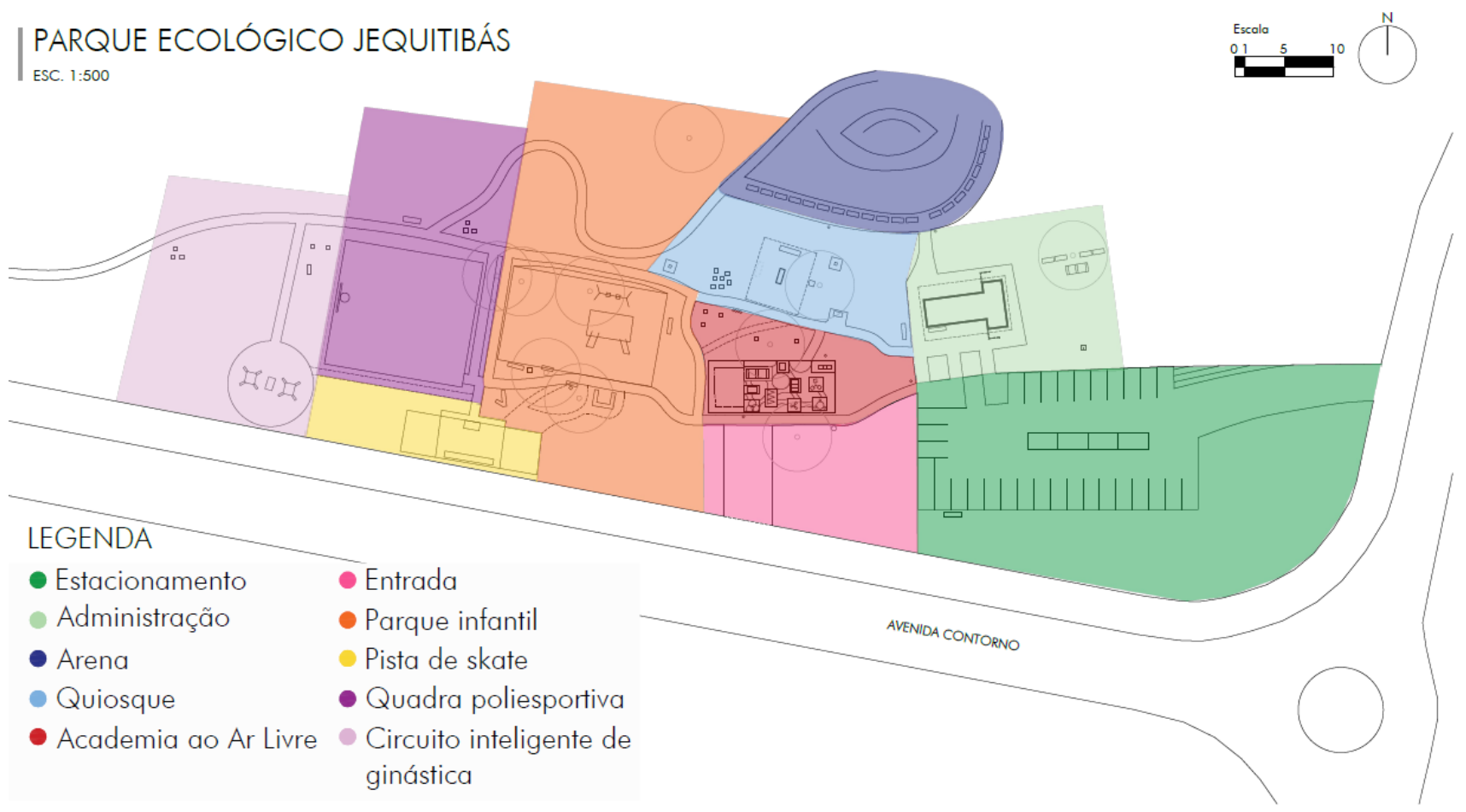

Fig. 03 Distribuição das Áreas-Alvos do Parque Ecológico dos Jequitibás. Fonte: Elaboração própria.

Os períodos em que foram realizadas as observações são: manhã (7h30 e 8 h), almoço (11h30 e 12 h) e tarde (15h30 e $16 \mathrm{~h}$ ) conforme os descritos no instrumento SOPARC. Porém, o período noturno (18h30 e 19 h) não pode ser realizado devido ao horário de fechamento do parque, que ocorre às 18h; por esse motivo, optou-se por realizar uma contagem antes de seu fechamento (17 h e 17h30).

Os dados utilizados na pesquisa passaram pelo filtro de que o entrevistado faça parte do grupo de pessoas idosas. As entrevistas semiestruturadas foram feitas entre os intervalos de contagem em campo, para compreender mais a fundo sobre questões de acessibilidade ao local, segurança, mobiliário, piso, equipamentos públicos, sua autonomia no espaço, impressões pessoais, desejos e arranjos sociais. Para 


\section{SÃOPAULO15 $\sim 17 \cdot$ LISBOA $25 \sim 26$ JUN 2020}

\begin{tabular}{lcccc}
\hline \multicolumn{5}{c}{ TERÇA sem AAL } \\
\hline 12.11 .2019 & \multicolumn{2}{c}{ Quantidade } & \multicolumn{2}{c}{ População } \\
Período & Idosa & Idoso & Soma & Perc. \\
Manhã & 2 & 8 & 10 & $56 \%$ \\
Almoço & 0 & 0 & 0 & $0 \%$ \\
Tarde & 3 & 0 & 3 & $17 \%$ \\
Fechamento & 3 & 2 & 5 & $28 \%$ \\
TOTAL & 8 & 10 & 18 & $100 \%$ \\
\hline
\end{tabular}

\begin{tabular}{lcccc}
\hline \multicolumn{5}{c}{ TERÇA com AAL } \\
\hline 26.11.2019 & \multicolumn{2}{c}{ Quantidade } & \multicolumn{2}{c}{ População } \\
Período & Idosa & Idoso & Soma & Perc. \\
Manhã & 10 & 9 & 19 & $42 \%$ \\
Almoço & 2 & 2 & 4 & $9 \%$ \\
Tarde & 1 & 7 & 8 & $18 \%$ \\
Fechamento & 6 & 8 & 14 & $31 \%$ \\
\hline TOTAL & 19 & 26 & 45 & $100 \%$ \\
\hline \multicolumn{5}{c}{} \\
\hline \multicolumn{5}{c}{ SÁBADO com AAL } \\
\hline 14.12.2019 & Quantidade & População \\
Período & Idosa & Idoso & Soma & Perc. \\
Manhã & 4 & 9 & 13 & $26 \%$ \\
Almoço & 2 & 3 & 5 & $10 \%$ \\
Tarde & 9 & 9 & 18 & $36 \%$ \\
Fechamento & 4 & 10 & 14 & $28 \%$ \\
TOTAL & 19 & 31 & 50 & $100 \%$ \\
\hline
\end{tabular}

\begin{tabular}{lcccc}
\hline \multicolumn{5}{c}{ SÁBADO sem AAL } \\
\hline 09.11 .2019 & \multicolumn{2}{c}{ Quantidade } & \multicolumn{2}{c}{ População } \\
Período & Idosa & Idoso & Soma & Perc. \\
Manhã & 2 & 6 & 8 & $33 \%$ \\
Almoço & 2 & 3 & 5 & $21 \%$ \\
Tarde & 0 & 0 & 0 & $0 \%$ \\
Fechamento & 4 & 7 & 11 & $46 \%$ \\
TOTAL & 8 & 16 & 24 & $100 \%$ \\
\hline
\end{tabular}

Tab. 01 População de idosos por período do dia. Fonte: Elaboração própria.

Durante os dias sem a AAL, houve períodos sem população de idosos no parque, como no horário do almoço de terça e da tarde de sábado. Já nos dias com equipamentos, a presença das pessoas idosas era constante em todos os períodos do dia. Em geral, a proporção de pessoas idosas realiza mais atividades moderadas do que vigorosas no parque, à exceção do período do sábado pela manhã e almoço, quando o PEC estava disponível. No entanto, nota-se que a presença da AAL aumenta, consideravelmente, o número de pessoas mais velhas que realizam atividades vigorosas.

Embora a pesquisa PDAD 2018 (Codeplan, Sefp e Gdf, 2018) aponte que na RA Sobradinho existam mais idosas, $60,60 \%$ (5.033), do que idosos, $39,40 \%$ (3.272), a população idosa masculina mostrou-se mais frequentadora do parque, tanto nos dias sem equipamentos (56\% na terça e $67 \%$ no sábado), quanto nos dias com AAL ( $58 \%$ na terça e $62 \%$ no sábado). Comparando-se os dias sem e com os equipamentos, essa proporção permaneceu praticamente igual (Tabela 02).

Porém, a população feminina é mais ativa - realiza atividades moderadas e vigorosas -, nos dias sem PEC, durante a semana ( $25 \%$ das idosas realizavam alguma atividade em comparação a $10 \%$ dos homens) e no final de semana (são $25 \%$ de idosas ativas em comparação a $19 \%$ de idosos), e no dia com PEC, durante a semana ( $68 \%$ das idosas ativas em relação aos $58 \%$ dos idosos), contudo no final de semana, com PEC, são os idosos os mais ativos (61\% de idosos para $53 \%$ de idosas). 


\section{SÃO PAULO15 17 LISBOA $25 \sim 26$ JUN 2020}

\begin{tabular}{lcccc}
\hline \multicolumn{5}{c}{ TERÇA sem AAL } \\
\hline 12.11 .2019 & \multicolumn{2}{c}{ Quantidade } & \multicolumn{2}{c}{ População } \\
Atividade & Idosa & Idoso & Soma & Perc. \\
Sedentária & 6 & 9 & 15 & $83 \%$ \\
Moderada & 2 & 1 & 3 & $17 \%$ \\
Vigorosa & 0 & 0 & 0 & $0 \%$ \\
TOTAL & 8 & 10 & 18 & $100 \%$ \\
\hline
\end{tabular}

\begin{tabular}{lcccc}
\hline \multicolumn{4}{c}{ TERÇA com AAL } \\
\hline 26.11 .2019 & \multicolumn{2}{c}{ Quantidade } & \multicolumn{2}{c}{ População } \\
Atividade & Idosa & Idoso & Soma & Perc. \\
Sedentária & 6 & 11 & 17 & $38 \%$ \\
Moderada & 8 & 11 & 19 & $42 \%$ \\
Vigorosa & 5 & 4 & 9 & $20 \%$ \\
TOTAL & 19 & 26 & 45 & $100 \%$ \\
\hline
\end{tabular}

\begin{tabular}{lcccc}
\hline \multicolumn{5}{c}{ SÁBADO sem AAL } \\
\hline 09.11 .2019 & \multicolumn{2}{c}{ Quantidade } & \multicolumn{2}{c}{ População } \\
Atividade & Idosa & Idoso & Soma & Perc. \\
Sedentária & 6 & 13 & 19 & $79 \%$ \\
Moderada & 2 & 1 & 3 & $13 \%$ \\
Vigorosa & 0 & 2 & 2 & $8 \%$ \\
TOTAL & 8 & 16 & 24 & $100 \%$ \\
\hline
\end{tabular}

\begin{tabular}{lcccc}
\hline \multicolumn{5}{c}{ SÁBADO com AAL } \\
\hline 14.12.2019 & \multicolumn{2}{c}{ Quantidade } & \multicolumn{2}{c}{ População } \\
Atividade & Idosa & Idoso & Soma & Perc. \\
Sedentária & 9 & 12 & 21 & $42 \%$ \\
Moderada & 7 & 9 & 16 & $32 \%$ \\
Vigorosa & 3 & 10 & 13 & $26 \%$ \\
TOTAL & 19 & 31 & 50 & $100 \%$ \\
\hline
\end{tabular}

Tab. 02 Níveis de atividades da população de idosos. Fonte: Elaboração própria.

As idosas utilizam, proporcionalmente, mais a área dos aparelhos nos dias com AAL, durante a semana ( $58 \%$ de idosas para $19 \%$ dos idosos) e no final de semana ( $37 \%$ de idosas para $26 \%$ dos idosos). Por meio da contagem e mapas comportamentais, pode-se comprovar a presença dos idosos por quase todo o parque, excluindo a área dos skatistas, em que em nenhum momento estiveram presentes, por se tratar de uma área em que há um grupo dominante de adolescentes. Nos dias sem PEC, era possível observar uma maior concentração de idosos em outros pontos do parque, como na área do quiosque de madeira (44\%), no dia de semana e na área do parque infantil (50\%), no final de semana. Nos dias com a academia ao ar livre, a presença era maior nos próprios equipamentos tanto durante o dia de semana (36\%) como durante o final de semana (30\%).

\section{Discussão}

Foi importante observar a importância que a presença da AAL exerce no Parque Ecológico dos Jequitibás, em Sobradinho-DF, para a população acima dos 60 anos, quanto à promoção da inclusão social entre os idosos e as demais gerações e na difusão do envelhecimento ativo. A idade média dos idosos entrevistados no parque é de 63 anos, o que condiz com os dados do PDAD 2018 quanto à faixa etária mais populosa dentre os idosos.

O parque é bastante frequentado pela população local e vizinha como a de Sobradinho II $(5 \mathrm{~km})$, Rota do Cavalo $(13 \mathrm{~km})$ e Fercal $(15 \mathrm{~km})$, para a realização de atividades físicas, recreativas, encontros sociais, descanso, momentos de contemplação e oração. Durante os dias com a academia, os mais velhos procuravam o parque em busca de atividades física para a melhora da qualidade de vida e saúde, e nos finais de semana o parque se tornou um lugar mais voltado para o descanso e contemplação, não deixando de lado as atividades físicas. Quanto aos dias sem a AAL, foi possível perceber que os idosos permaneceram pouco tempo no parque, por não existir atrativo. 


\section{SÃO PAULO15 $\sim 17 \cdot$ LISBOA $25 \sim 26$ JUN 2020

A pesquisa partiu do pressuposto de que, com a retirada dos equipamentos ao ar livre, os idosos iriam buscar alternativas de exercícios, caminhada ou alongamentos. Os resultados revelaram que, nos dias sem a academia, o total de idosos sedentários é mais que o dobro em relação aos dias com aparelhos, sendo a diferença nos dias de semana de $38 \%$ para $83 \%$ e durante a semana de $42 \%$ para $79 \%$. Ainda, nos dias sem os equipamentos, há uma discrepância de proporção entre os níveis de atividades sedentárias e as moderadas e vigorosas. Pelas entrevistas, foi possível perceber a falta que os aparelhos de ginástica fizeram, como relatou a Sra. Leni, de 65 anos: "Faz falta para os exercícios e para as conversas". Em todos os dias de pesquisa foi possível perceber que os encontros e as conversas prevaleciam no parque, como confirmou Dna Anísia Gomes, de 66 anos, que gosta de ir ao parque para se movimentar, ver os outros e dar bom dia, para poder iniciar uma conversa.

É interessante observar que a população relativa de idosos permaneceu a mesma durante os dias de semana e final de semana sem AAL (5\%) e que nos dias com a presença da academia esse percentual tenha aumentado (sábado $8 \%$ e terça-feira 13\%), mostrando como os equipamentos são um atrativo para a população mais velha. Revela, ainda, que os idosos frequentam mais o parque durante a semana do que o final de semana e que, durante a semana, preferem o período matutino. O mesmo ocorreu em um estudo realizado com o mesmo instrumento SOPARC, no Brasil, em Presidente Prudente/SP, no Parque do Povo, em que, para a população acima de 60 anos, "o período da manhã foi o favorito e sua frequência diminuiu aos finais de semana" (Xavier, Felipe e Arana, 2018: 91).

Durante os períodos do almoço e da tarde foi possível perceber uma diminuição da frequência dos mais velhos, com exceção do sábado em que havia os equipamentos, em cuja presença foi menor no período da manhã e almoço. Em conversas com os mais velhos foi possível perceber que eles evitavam frequentar o parque durante o período em que o sol está a pino e preferiam ir cedo do que a tarde, devido a maior quantidade de pessoas na rua e pela sensação de segurança por estar clareando o dia.

Nos dias com a AAL a atividade que foi mais observada dentre os idosos foi a caminhada, seguida de exercícios físicos nos aparelhos de ginástica. O parque não proporciona pista de caminhada, apenas um trecho calçado mais extenso que entra na mata e logo vira trilha, possui $400 \mathrm{~m}$, feitos em blocos de concreto intertravado, assim como alguns outros pequenos caminhos existentes. Já a pista externa de caminhada, local onde a maioria dos idosos efetivamente realiza seus exercícios, é de concreto e possui cerca de $1 \mathrm{~km}$ paralela à entrada do parque e ao longo de seu comprimento, ainda que se estenda bastante fora deste perímetro. Muitas pessoas idosas realizam as atividades físicas na área da AAL na terça $(58 \%$ das idosas e $19 \%$ dos idosos) e no sábado (37\% das idosas e $26 \%$ dos idosos) e somente alguns idosos do sexo masculino foram contabilizados na área do circuito inteligente de ginástica (terça 8\% e sábado 19\%).

Os resultados indicam que os parques com os aparelhos ao ar livre são muito mais atrativos aos idosos e ajudam na promoção do envelhecimento ativo do que quando não possuem esses equipamentos. Isso corrobora com a pesquisa de Presidente Prudente, onde "nas 'academias da terceira idade' instaladas ao longo do Parque do Povo, destacavam-se pela presença deles (idosos) ao longo das observações" (Xavier, Felipe e Arana, 2018: 92). Além da questão física, há o estímulo ao convívio social, geracional e intergeracional, proporcionado pelo espaço, pois, ao realizar os exercícios, as pessoas presentes no local acabam por trocar algumas palavras de saudação, ideias e boas conversas. Nos dias com aparelhos pôde-se observar pessoas de todas as idades na área do PEC, o local mais frequentado pelos idosos. 


\section{SÃO PAULO15 17 LISBOA $25 \sim 26$ JUN 2020}

Apesar dos equipamentos serem previstos para uso acima dos 12 anos, a presença de placas de advertência com dizeres "proibido crianças" presentes na AAL não são bem aceitas pois, ao afastar as crianças do convívio com os mais velhos, acaba por se perder um estímulo à presença das duas gerações e uma oportunidade valiosa de aprendizado aos mais jovens. Já quando o convívio é permitido, ajuda-se na promoção de crianças mais conscientes com os cuidados com os idosos e no aprendizado da própria cultura.

Não foram observadas ações governamentais de promoção à saúde dos idosos nos dias de pesquisa, abrindo-se oportunidade para atuação do poder público. As políticas públicas são importantes quesitos para orientação aos mais velhos quanto à realização dos exercícios de maneira correta e na promoção de uma vida mais ativa. Como comentou o Sr. Flávio Nunes, de 63 anos: "não tem nenhum profissional para orientar o uso (dos aparelhos de ginástica). A pessoa pode se machucar e se distender e nem sabe o porquê de ter acontecido".

Sobre o quesito acessibilidade no PEC, foram poucos os idosos que reclamaram dessa questão. No geral, a maioria diz-se satisfeita com o que possui. Porém, a pavimentação local não é adequada para o público em questão, uma vez que é composta por pequenos desníveis entre blocos de concreto e o piso com desenhos geométricos em grama e terra. Vale alertar para a falta de barras de apoio próximas aos equipamentos para auxílio dos idosos no ato de sentar e levantar e para chegar até outro equipamento. Seria interessante, também, que a área possuísse bancos na altura adequada e com encosto para que os idosos possam descansar, conversar e permanecer por mais tempo no parque.

\section{Conclusão}

A pesquisa amostral, com 33 idosos entrevistados, aponta a importância da AAL e sua relação espaçosociedade, por mais que os usuários alertem quanto à manutenção e que várias melhorias são necessárias. Observou-se, também, que a comunidade está aberta para receber os idosos e que a própria comunidade mais velha se apodera do parque como sendo realmente seu.

"Falta um lugar específico para os idosos, com banquinhos na altura boa" foi o que relatou Dna. Deusnira, de 71 anos. Hoje, no parque, o único espaço destinado para os idosos é a AAL. Faltam espaços aconchegantes e estimulantes para os mais velhos, com mesas, bancos para fazer um lanche da tarde, jogar carteado, ou uma minibiblioteca. Um espaço que estimule os idosos a passar mais tempo no parque, não ir só para a realização de exercícios e depois ter que voltar para casa porque não existe um local a mais para que ele possa contemplar ou se socializar.

Abre-se caminho para discussões de como os espaços públicos existentes precisam ser melhorados e adaptados para abranger o maior número de pessoas das mais variadas idades e gêneros. Os espaços públicos existem para servir à comunidade e proporcionam uma vitrine importante para apresentação e divulgação de políticas públicas. Pondera-se que, ao construir e pensar em espaços que atendam ao público mais velho, não se está segregando essa parcela da sociedade, mas permitindo que todas as pessoas possam usufruir de um espaço com mais acessibilidade, independência, segurança e autonomia, além de promover qualidade de vida e inclusão social. 


\section{XII $\quad$ SÃO PAULO $15 \sim 17 \cdot$ LISBOA $25 \sim 26$ JUN 2020}

\section{BIBLIOGRAFIA}

BRASIL (2010). Lei Complementar no 827, de 22 de julho de 2010, Brasília, Institui Sistema Distrital de Unidades de Conservação da Natureza.

BRASÍLIA (2017). Decreto oㅜ 38.368, de 26 de julho de 2017, Brasília, Recategorização do Parque dos Jequitibás.

CODEPLAN, SEFP e GDF. (2018). Pesquisa Distrital por Amostra de Domicílios 2018: Distrito Federal. Ed. Brasília, DF: CODEPLAN.

GDF. (2019). Conheça a RA V. Administração Regional de Sobradinho. Disponivel em: <http://www.sobradinho.df.gov.br/category/sobre-a-ra/conheca-a-ra/>. Acesso em: 23 jul 2019.

GEHL, J. (2011). Life between buildings: using public space. Tradução de Jo Koch. 6ª . Ed. Washington: Island Press. 208p.

GEHL, J.e SVARRE, B. (2018). A vida na cidade: Como estudar. Tradução de Anita Di Marco. 1a. Ed. São Paulo: Perspectiva. $184 \mathrm{p}$.

IBRAM. (2020). Unidades de Conservação. Brasília Ambiental. Disponivel em: <http://www.ibram.df.gov.br/unidades-de-conservacao/>. Acesso em: 25 jul 2020.

ICMBIO. (2020) Visite os Parques. Ministério do Meio Ambiente. Disponivel em: <https://www.icmbio.gov.br/portal/visitacao1/visite-os-parques>. Acesso em: 10 ago 2020.

INSTITUTO DE MEIO AMBIENTE E DOS RECURSO HÍDRICOS. (2013). Guia de parques do Distrito Federal. Brasília, DF: IBRAM.

INSTITUTO SOCIOAMBIENTAL. (2013-2016). Acervo Socio Ambiental. Instituto Socioambiental. Disponivel em: $\quad$ https://acervo.socioambiental.org/acervo/documentos/decreto-n-16239-de-281294-cria-o-parque-dosjequitibas>. Acesso em: out 2019.

MCKENZIE, T. L. e COHEN, D. A. (2006). System for Observing Play and Recreation in Communities SOPARC, Description and Procedures Manual. San Diego State University. Coronado, CA, p. 17. 2006.

PIERI, B. F. D. (2015). Motivação para a prática de exercícios físicos em academias ao ar livre em praças públicas. Universidade Estadual de Campinas. Campinas, p. 77.

SECRETARIA DE EDUCAÇÃO GOVERNO DO ESTADO DO PARANÁ. (2014). Os desafios da escola pública paranaense na perspectiva do professor PDE. Produções didático-pedagógicas. Paraná: Governo do Estado, v. II, 2014. 37 p. ISBN ISBN 978-85-8015-079-7. Cadernos PDE.

SILVA, E. A. R. D.; ELALI, G. A. (2015). O papel das praças para o envelhecimento ativo sob o ponto de vista dos especialistas. Pesquisas e práticas psicossociais, São João del-Rei, jul/dez.

TENORIO, G. D. S. (2012). Ao desocupado em cima da ponte. Brasília, arquitetura e vida pública. Universidade de Brasília, UnB. Brasília, DF, p. 391.

WORLD HEALTH ORGANIZATION. (2005). Envelhecimento ativo: uma política de saúde. Tradução de Suzana Gontijo. 1a. ed. Brasília, DF: Organização Pan-Americana da Saúde, Opas, OMS. 


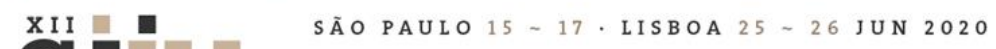

WORLD HEALTH ORGANIZATION. (2007) Age-friendly cities projet methodology: Vancouver Protocol. Geneva, Switzerland: WHO.

XAVIER, F. B., FELIPE, J. e ARANA, A. R. A. (2018). O parque verde urbano: características do uso através de observação sistemática. Revista Brasileira de Gestão Urbana, v. 10, Supl. 1, 82-95. ISSN DOI: 10.1590/2175-3369.010.SUPL1.AO05, ISSN 2175-3369. 